\title{
Extracts from circular to Secretaries of Regional Hospital Boards and Boards of Governors
}

Reference B(3)/P243/021

\author{
Postgraduate medical and dental \\ education
}

\section{Payment of expenses of practitioners engaged in college and related activities}

1. There has been considerable expansion in recent years in the work of the various colleges, faculties and similar bodies in the field of postgraduate medical and dental education. Much of this activity has been directed towards defining appropriate programmes of higher specialty training. Thus, for example, in the surgical and medical specialties the appropriate colleges and other bodies have been much concerned with establishing the type and length of post-Fellowship or Membership experience required in order to train a doctor to the stage where he is ready to assume consultant responsibilities.

2. It is understood to be the practice of some colleges, when making arrangements for their representatives to visit hospitals for the purpose of assessing training facilities, to ask the hospital authority concerned to meet the travelling and subsistence expenses incurred by their representatives; and hospital authorities have customarily been willing to do so. The Department considers that in these circumstances it is proper for hospital authorities to assist in meeting such expenses as may be incurred by college visitors (whether or not the visitors in question are NHS staff) and that the rate of travelling and subsistence allowances should be those agreed by the General Whitley Council for Class 1 officers. It would seem appropriate for the receiving hospital authority to meet these expenses rather than the employing authority of the visitors. Where a single programme of visits includes visits to RHB and BH hospitals it may be most convenient if a single claim is submitted to the regional authority.

3. NHS consultant staff and university teachers with NHS honorary consultant contracts also play a major part in the professional postgraduate medical and dental education work of colleges and similar bodies through serving on relevant committees or by contributing to conferences and other meetings arranged by these bodies for the furtherance of this work. They serve on the Joint Committee on Higher
Surgical Training (which represents the four colleges of surgeons in the British Isles, together with the Association of Professors of Surgery and a number of the specialist surgical associations), the Joint Committee on Higher Medical Training (representative of the four colleges of physicians, the Association of Professorial Heads of Departments of Medicine and Paediatrics, and specialist societies) and on similar committees in dentistry and anaesthetics. The work of these and similar committees in other specialities is concerned with the development and implementation of programmes or schemes of higher specialty training. The Department considers that it would be reasonable for hospital authorities to grant special leave to consultants (including honorary consultants) who are members of committees engaged in this work and to assist in meeting the travelling and subsistence expenses they may incur. The rates agreed by the General Whitley Council for Class 1 officers should be applied. It would be expected that doctors and dentists engaged in these activities and who wished to claim travelling and subsistence expenses would seek the prior approval of their employing authority through the appropriate channels.

4. A list of the main committees known to be currently active in the development of specialty training schemes is appended for guidance. This list of committees is not intended to be exclusive or to interfere with boards using their own judgement in relation to payment of expenses for attendance at other committees or conferences. It is not practicable to draw up a comprehensive list of the bodies which might be involved, but is suggested that the main criteria to be applied should be that the activity should be wholly or substantially concerned with the development of postgraduate education for NHS staff within a recognised specialty or sub-specialty and that it should be of clear value, directly or indirectly, to the NHS.

Department of Health

R. Cattran and Social Security Alexander Fleming House Elephant and Castle London SEI

17 November 1972 